\section{Enhancing Secondary School Students' Reflective Thinking Through a Suggested Model Based on Constructivism}

\section{Main Researcher:}

Second Researcher:

Third Researcher

1 University Name \& City:

2,3 University Name \& City:

* Corresponding author:

E-mail address:

\section{Kholoud I. Sorour}

Dr. Magdy S. Aqel

Dr. Jaber I. Abu Shawish

Islamic University of Gaza

Al-Quds Open University

https://doi.org/10.33976/IUGJEPS.29.4/2021/39

Enhancing Secondary School Students' Reflective Thinking Through a Suggested Model Based on Constructivism

\title{
Abstract:
}

The aim of this study was to investigate the effect of a suggested model RW based on constructivism on the reflective thinking of the secondary school students in Gaza. The sample consisted of (87) female students in two groups; control 43 and experimental 44 . The researchers used experimental design of two randomly chosen groups with the same pre and post tests for each. Different statistical tests included in the Statistical Package for the Social Sciences (SPSS) were used to analyze the data collected while answering the study questions and testing the hypotheses. The results showed that there were statistically significant differences at $(\alpha \leq 0.05)$ between Experimental group and Control group in relation to the reflective thinking in favor of Experimental group. Also, the effect size of using the model based on constructivism was significantly large on students' reflective thinking. The researchers strongly recommended training teachers to design models based on constructivism to enhance students thinking in general and particularly reflective thinking. Also, to carry out further research on the effect of using constructivism models in education and probable ways to enhance thinking skills of the secondary school students jrevise the last sentence

Keywords: guiding principles, meta-analysis, reading research.

\section{اثز نموذج مقترح قائم على البنائية في تصسين مهارات التفكير التاملي لاى طالبات الصف الثاني عثر في غزة}

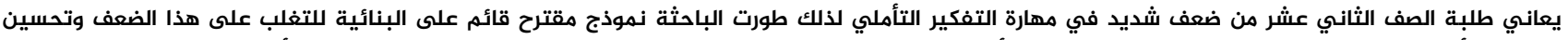

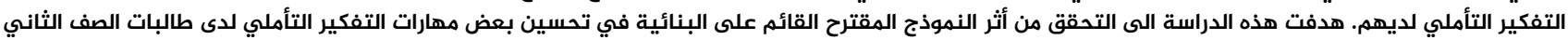

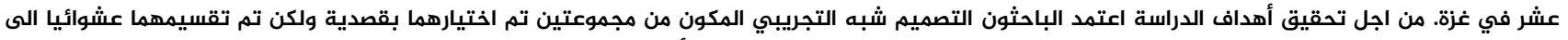

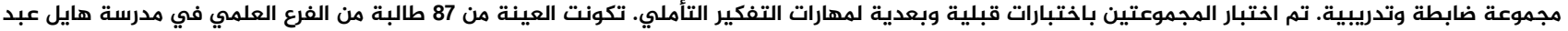

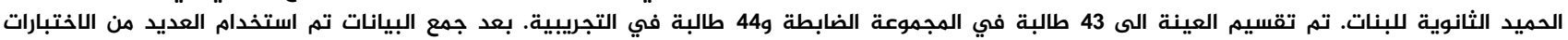

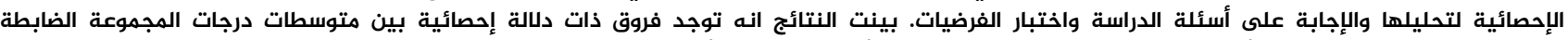

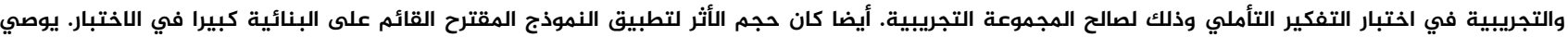

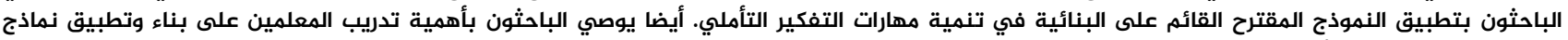

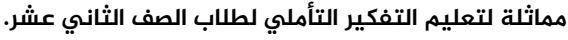




\section{1-Introduction:}

The current century witnesses very rapid and continuous development worldwide in which has a very dynamic and crucial effect on societies. These societies tend to spend time, effort, and money in order to update their educational systems to produce efficient learners who are capable of competing in this world. Therefore, they try hard to adopt the most effective strategies in teaching and learning. Also, they tend to change educational curricula to match with these developments and to gain high learning outcomes.

Palestine is a country that has been under occupation and siege for decades. It has little or nearly no natural resources. Poverty and unemployment take over. What Palestine needs now is a generation of high-qualified, competent, and skillful learners who can compete worldwide. These learners are expected to solve the problems they face using high order thinking skills as well as their communication skills. The importance and effect of the abilities to "think differently" and "language competency" are gradually increasing. There is a need for producing such learners nowadays in order to solve the problems they face and overcome the obstacles on the way.

This matches well with the main goal of constructivism; producing learners who are able to think reflectively is one of the main aims of a constructivist approach to education. Here, the role of education appears clearly to achieve this stage of thinking by using appropriate strategies and systematic plans. Constructivism is fundamental to modern teaching techniques because it simply calls for learning by doing, reflecting, adapting, and problem- solving (Gray, 1997).

At the same time, reflective thinking is supposed to be developed as a result of employing this model in teaching writing.

Why reflective thinking? "Reflection leads to growth of the individual - morally, personally, psychologically, and emotionally, as well as cognitively". (Branch \& Paranjape, 2002, p. 1187).

Reflective thinking can help learners to better understand their qualities and whether they are strong or weak. Also, to question and set their underlying values and beliefs. In addition it can constitute to identify and challenge probable assumptions on which their ideas, feelings and actions are based. Moreover, reflection helps to realize areas of possible bias or discrimination. As a result of all what has been mentioned, it leads to acknowledge the learners fears, and identify possible inadequacies or areas for improvement.

Constructivism as a paradigm of teaching and learning is one of the methods adopted by many educators. It is different from the traditional view because it relies mainly on the belief that knowledge is not a thing that can be simply given by the teacher at the front of the room to students in their desks. Rather, it is basically constructed by learners themselves during an active progressive process; learners are supposed to be the builders and producers of meaning and knowledge.

Piaget (1977) asserts that "learning occurs by active construction of meaning, rather than by passive recipients". He illustrates that when learners face an experience or a situation that conflicts with their current way of thinking, they certainly face a state of imbalance. They have to then alter their thinking to restore the balance they lost during this process. To do this, "they make sense of the new information by associating it with what they already know, that is, by attempting to assimilate it into our existing knowledge". If they can't do this, they accommodate the new information to their old way of thinking by restructuring our present knowledge to a higher level of thinking" (Gray, 1997). Kelly (1991) has a similar theory of personal constructs. He suggests that learners look at the world through mental constructs or patterns that they create. They develop ways of understanding the world based on their previous experiences.

\subsection{Objective of the study}


The current study aims at accomplishing many goals. First, designing a model based on constructivism RW. Second, the study aims to check the effect of the model on the participants' reflective thinking.

\subsection{Statement of the Problem}

The researchers have been teachers of English as a foreign language for a long time. Teaching secondary school and university students, they noticed major weakness in thinking skills and in particular reflective thinking for the majority of the students they teach. Unfortunately, most students do not get the chance to practice thinking at schools. In fact, they tend to memorize instead of generating new ideas. Moreover, as Irfaner (2006) pointed out that the lack of reflective thinking skills employed within the classroom notably weakens the students' opportunity for higher-level learning.

\subsection{Questions of the study:}

The study attempts to answer the following questions:

1- What are the elements of the suggested model that is supposed to help to develop reflective thinking and writing skills for the twelfth graders?

2 - Are there any statistically significant differences at $(a \leq 0.05)$ between the mean scores of the experimental group and the control group on the post administration of the reflective thinking test?

\subsection{Hypothesis}

Based on the questions of the study, one hypothesis was formulated:

1- There is no statistically significant difference at $(\mathrm{a} \leq 0.05)$ between the mean score of the experimental group and the control group on the post administration of the reflective thinking test favoring the experimental one.

\subsection{Significance of the study}

The current study is a unique one. During reviewing literature, so rare studies dealt with reflective thinking and none has built models based on constructivism to enhance reflective thinking.

The study attempts to accomplish the following:

1- Suggesting a new model for enhancing the twelfth graders reflective thinking skills.

2- Training the Twelfth graders on the new model for developing reflective thinking skills.

3- Raising the awareness of English language curricula developers to the importance of using the new model that leads to a positive serious change in the twelfth graders reflective thinking.

4- This study will be a contribution to the art of teaching. When reviewing literature, few studies dealt with reflective thinking and rare combined constructivism based models with reflective thinking. Moreover, teachers will gain great benefit from it as they will have a good idea on how to build models based constructivism to enhance teaching and learning process. In addition, people in charge at the ministry of education will be interested in preparing appropriate materials to train teachers to build such models. Accordingly, the twelfth graders will gain the harvest of this study.

\subsection{Limitations of the study}

This study had potential limitations as follow:

Sample bias: the students have been already assigned to classes when the researcher carried out this study. The issue here was to randomly choose the control and experimental groups.

Time constraints: the twelfth-grade students have very limited periods across the scholastic year which usually starts in September and ends in April with 4 English periods a week. It was really a kind of struggle to get permission from the Palestinian ministry of education to carry out this study on twelfth-grade students. However, the researchers managed to get it in time to start. It took 10 
weeks to teach the experimental group students using the suggested model RW with an average of 2 periods a week; one period for reading while the other for writing.

\subsection{Procedures of the study}

In order to achieve the goal of the current study, the researchers followed various procedures. These include holding a workshop with some English teachers of the twelfth grade to discuss the major weakness areas in reflective thinking. In addition, the researchers have surveyed the related literature and previous studies that dealt with constructivist models in teaching thinking skills. Accordingly, the researchers built up the model that is based on constructivism Read to Write (RW). Then they consulted some university and school teachers to modify the model according to their notes. Here the time had come to build an appropriate reflective thinking test. Since one of the researcher work at a secondary school, she randomly chose two twelfth grade classes at "Hayel Abdul Hameed Secondary School". They were separated into control and experimental groups.

To check the validity and reliability of the test, it was implemented on a pilot sample of 30 students who have the same characteristics as the sample of the study then to the two groups at the same time as a pretest.

One of the researchers taught the experimental group according to the model RW, while the control group was taught by the traditional way. After 10 weeks, the researcher implemented the same test as post-tests on both groups. Finally, the data had been collected and analyzed using SPSS to show the results.

\subsection{Definitions of key terms \\ 1.9.1 Constructivism}

Constructivism is a paradigm to learning that holds that $12^{\text {th }}$ graders actively construct or produce their own knowledge and that reality is determined by the experiences of the learner (McLeod, 2019). Constructivism is the theory that the researchers derive the notions of the suggested model RW from in this study.

\subsubsection{Reflective thinking}

Reflective thinking is an active process that learners interpret and evaluate their experiences, check that they make 'sense' to them, create meaning, justify actions and solve problems (Deway, 1997). The current study examines some of reflective thinking skills including; inference, assumption, deduction, interpreting information and argument.

\subsubsection{Suggested model}

A model of teaching that builds teaching and learning environment. This includes the behavior of teachers and students while the lesson is presented through that model. The current model RW is based on constructivism theory. It is based on the idea that learning is constructed. This model aims at enhancing writing skills through reading among the $12^{\text {th }}$ graders during the application of this model's procedures and activities.

\subsubsection{Twelfth graders}

The students who are the twelfth grade (Tawjihi). They study English language as a main subject. At the end of the year, they have national exams.

\section{2-Literature Review}

\subsection{Constructivism}

"Constructivism has roots in philosophy, psychology, sociology, and education. But while it is important for educators to understand constructivism, it is equally important to understand the implications this view of learning has for teaching and teacher professional development" (Hoover, 1996). 
Philosophers such as Dewey, Piaget, and Vygotsky had various views and ideas on constructivism despite being arguing basically around similar epistemology and ontology. To put it simply, they interpreted the same concept from their different angles, experiences, minds, and worlds. Each of them constituted to more clarification that made us better understand it. "Constructivism is in the mind of knowers where they construct a reality, or interpret it, relying on their experiences, and how they deal with how they are constructed" (Brooks \& Brooks, 1999; Jonassen, 1992).

Experience is a vital concept in constructivism. In this area, Deway stated once "knowledge is the life itself and it is the learners' experiences, not something abstract out there independent from the learner" (Dewey, 1916, 1938/1997). Hence, teaching and learning processes should be related to and based on the real practical world. To achieve this, every component of the teaching and learning process should be designed and formed in a way where the students are given the chance to talk and ask reflective questions, share ideas and experiences, and exchange knowledge interactively (Brooks \& Brooks, 1999).

Since it appeared in the 1990s, constructivism has brought a pedagogical breakthrough around the modern world, which certainly affected the research in many pedagogical fields including second and foreign language acquisition. Guided by the notions of behaviorism and cognitivism, constructivism principles have led to developing many teaching models as scaffolding instruction, anchored instruction, and random access instruction and so on. These models confirm that situation creation, teamwork, and autonomous study are important in creating appropriate learning environment. Learning itself is a process of structuring in which learners actively construct their knowledge by themselves or with the help of others. As Bruner stated "Learning is also an active process by which learners construct new ideas on the basis of their present and previous knowledge" (Bruner, 1966).

Vygotsky (1978) explained that "constructivists place the learner at the center of the equation; the idea is that the learner constructs knowledge rather than passively absorb it". In other words, constructivism's main idea is that learning is constructed; that learners build new knowledge and ideas upon the basis of previous knowledge and learning.

Hoover (1996) confirmed this by stating that "two important notions orbit around the simple idea of constructed knowledge. The first is that learners construct new understandings using what they already know". In other words, learners usually come to learning situations with prior knowledge that gained from other learning situations. This prior knowledge inevitably affects what new or modified knowledge they will construct from new learning experiences.

The second notion is that learning is active process not passive one. Learners guide the comprehension enlightened by what they face in the current learning situation. The comprehension can change according to new experiences. These learners remain active throughout this process: they are supposed to apply understandings, note all the relevant elements found in the new learning experiences, judge the consistency of prior and emerging knowledge, and based on that judgment, they can modify knowledge (Hoover, 1996).

Why is constructivism important? Gray (1997) answers this stating that educational curricula and teaching methods are changing. He wrote "One component of the current redevelopment of all subject area curricula is the change in focus of instruction from the transmission curriculum to a transactional curriculum". On one hand, in a traditional curriculum, a teacher more often conveys knowledge to the learners who just listen passively without any response and only gain facts and information. On the other hand, in a transactional curriculum, students are actively involved in their learning to reach new comprehension and construct their own knowledge.. 
Constructivist teaching process tends to enhance thinking in general and creates active and motivated learners. Zemelman et al (1993) elaborate that learning requires inventing and creating new ideas and thoughts. They suggest that the principles of constructivism can be incorporated into the curriculum. They also explained that teachers accordingly create environments in which learners can build their own understandings. Fosnot (1989) recommends that "a constructivist approach be used to create autonomous learners, inquisitive thinkers who question, investigate, and reason. A constructivist approach frees teachers to make decisions that will enhance and enrich students' development in these areas".

\subsection{Reflective Thinking}

Dewey (1997) states that reflective thinking is "active, persistent and careful consideration of any belief or supposed form of knowledge in the light of the grounds that support it and the further conclusion to which it tends". He suggests that this kind of thinking is partly different from the other kinds of thinking and is unique by itself. Dewey adds that reflective thinking comes in a previous stage to action in response to things that confuse us. It focuses on future actions rather than simply pondering the past. (Leung \& Kember, 2003).

What really important is the educational concept of thinking. Ruggerio (2012) provides a useful working definition of thinking: "Thinking is any mental activity that helps formulate or solve a problem, make a decision, or fulfill a desire to understand." This definition clarifies that such type of thinking is required in education. Education prepares learners for life by giving the proper skills needed to develop and make progress in their future.

Other researchers such as (Lee, 1996; Tweed \& Lehman, 2002) stated that the concept of reflective thinking is not new at all and rooted in the Confucian tradition. Despite this, John Dewey is the originator of the concept of reflective thinking. He is the first one who calls for it as an aspect of learning and of adult education (Bolton, 2010; Kember et al., 2000; Leung \& Kember, 2003).

Another definition of it was by Mezirow (1991), who defined reflective thinking as "the critique of assumptions about the process or content of problem-solving and goes on to distinguish problem posing, raising questions about the premises or presuppositions, from problem-solving".

Porntaweekul, et.al (2015) suggest that reflective thinking differs from one to one and is largely affected by an individual's behaviors. It deals with making learners to deduce meaning out of an experience, analyze and criticize elements. Then it can be transmitted through spoken, written, or other forms of expression. I.e. breaking a complex subject into smaller parts to gain a better understanding of it. And, criticizing involves a questioning, in addition to checking assumptions. Accordingly, a learner who engages in reflective can be developed through this kind of practice. Furthermore, learners can develop during understanding, internalizing, and applying some key concepts to evaluate their own learning.

Reflective thinking and critical thinking are synonyms. They both call for wrestling with real problems that exist in complex situations. Facione (1990), and other researchers such as Mann (2009) and Wolters et al. (2014) agree that reflective thinking as a competency for wrestling with real-world, ill-defined, wicked, messy, or indeterminate problems rooted in complex environments.

Kember et al. explain "that reflective thinking include four dimensions as habitual action, understanding, reflection, and critical reflection". They illustrate that this classification can be used to evaluate the degree of the students' writings, compositions, dairies, and their response to openended questions (Kember, 2000). 
Habitual Actions: Habitual action is about the idea that when learners learn something and use it frequently, it automatically becomes a conscious thought. (Kember et al., 2000, p. 383). Habitual action happens when a learner responds to a requirement by providing an answer without trying to reach a comprehension of the underlying concept (Kember et al., 2008). These are the actions that have been learned before, and mastered through frequent use and started to be done automatically. I.e. they become a part of their habits. Using a keyboard, driving a car can be given as examples of this level. Schon (1983) called this type of behavior knowing-inaction.

Understanding: Mezirow describes this kind of thinking as thoughtful action which is cognitive process (Mezirow, 1991). This type occurs when learners makes use of existing knowledge, without attempting to appraise that knowledge. Thus, learning remains within preexisting meaning schemes and perspectives. Most content of textbooks which takes place in schools and universities is best classified as thoughtful action. Understanding is different from habitual action that it is an individual attempting to reach an understanding of a concept or topic.

- Reflection: "Reflection is active, persistent, and careful consideration of any beliefs or supposed form of knowledge in the light of the grounds that support it and the further conclusion to which it tends" (Kember et al., 2000). Reflection is different from understanding that the process of reflection, as the name suggest, reflects personal experiences.

- Critical reflection: Critical reflection is the higher form of reflective thinking that occurs when a learner becomes aware of why they perceive, think, feel, or act as they do (Leung \& Kember, 2003). Critical reflection is reflection in addition to realizing why the specific knowledge and beliefs were applied in particular to the new situation and the potential consequences resulted from that application. It includes undergoing a transformation concepts and beliefs (Mezirow, 1991). A number of 43 set of beliefs and values govern the actions that learners may have almost unconsciously assimilated from their experiences and environment. To change a certain perspective, a learner needs to recognize and change his assumptions. To undergo critical reflection, though, it is necessary to carry out a critical review of pre assumption from conscious and unconscious prior learning and their consequences. Definitely, these such ingrained assumptions are very hard to change, because most people or learners are unaware of their own existed assumptions. Of course, a one can not change a thing that they don't realize. The word "awareness" becomes very essential here.

According to Dewy (1 933) a deep level of reflection can be illustrated by differentiating critical reflection and less critical reflection. He argues, "A person who was not sufficiently critical could reach a hasty conclusion without examining all the possibilities".

Dewey illustrates that reflection as a concept and purposes it served are as following:

1. Reflection means that a learner moves from one experience into another. During this process, he passes through deeper understanding of its relationships with and connections to other experiences and ideas. In other words, it is a meaningful process guarantees lifelong learning, this, of course, will be reflected as progress on the learner and, ultimately, society.

2. Reflection has roots in scientific inquiry as it is a systematic, rigorous, disciplined way of thinking.

3. Reflection is part of everyday actions that happen in society.

4. Reflection needs the attitudes that value the individual and intellectual growth of oneself and of others (p. 485 as cited in Buck, 2017).

Reflective thinking includes acquiring many skills. These vary from inference to analyzing to problem solving. In this study, the researcher adopted some of the reflective thinking skills. These are: 
1. Inferences; inferences are the steps of reason that leads assumptions to deduction.

2. Assumptions; assuming that something is correct without proof.

3. Arguments; "a coherent series of reasons, statements, or facts intended to support or establish a point of view"(Webster, 2020)

4. Interpreting Information; means to give, provide, or explain information.

5. Deductions; deriving a conclusion by reasoning.

\subsection{Constructivism and Reflective thinking}

The main goal of a constructivist approach is to produce reflective thinkers. This goal is also one of Dewey's pragmatism main objectives. Dewey (1933) stated that "reflective thinking adds meaning to the experience through its reorganization and reconstruction and leads the way for further goals requiring more comprehensive tasks". Osterman (1998) wrote that both constructivism and reflective thinking have basic assumptions about knowledge and learning. Both involve the belief that learning process should have integral and interdependent ideas and actions. These are considered to be essential factors of the learning process. He adds "Constructivism and reflective thinking both emphasize the importance of conceptual conflict, a "perturbation," or problem as a stimulus for learning. The notions of constructivism and reflective thinking suggest that these general strategies lead more effectively to learning in which the ultimate goal is competent action or improved performance". These strategies should redefine the learning objectives, in addition to their applications. This, accordingly, facilitates the integration of theory into practice.

Reflective thinking and constructivism allow learners to feel responsible for their learning, to set their objectives, and to participate in learning processes. It also requires the students to work to achieve their learning objectives in which they have set and turn into the behavior. Then, they evaluate the performance they give and have a view of the progress they make, carry out a discussion about the final product. In this way, it will be possible to get benefits from the experience for further experience. Indeed, this is considered as complete successful.

In fact, teachers in particular are the ones who are expected to upgrade their students' reflective thinking skills by using certain strategies and techniques (Demir, 2015). These strategies should be designed accurately to match with the learners styles of learning and to the contents objectives. Teachers, themselves, need much training on how to design such learning environments.

\subsection{Reflective Thinking and Teaching Learning process}

The learning process involves many vital aspects including one aspect that is really essential; reflective thinking (Dewey, 1997). "It cultivates meaningful learning in the teaching and learning processes and helps students and educators alike to develop specific skills 34 that may assist them to be more critical and to develop expertise in their areas of professionalism" (Phan, 2007). Actually, when learners learn to think critically, they also learn how to make reflective judgments (Facione, 1998).

According to Shandomo (2010), reflective thinking certainly affects teachers' ability to question events, reflect, and gain different prospective on them. Obviously, developing different perspectives is important in today's education. For this reason and for many other reasons, the preparation of teacher in education is very essential. Reflective teachers make sure that their students acquire reflective thinking. They support the development and teaching of this type thinking; in this context, they contribute at raising of people with positive traits that are much looked for by advanced and productive societies (Duban \& Yanpar Yelken, 2010).

Osterman (1998) stated that both constructivism and reflective thinking set some criteria to evaluate learning situations and for suggesting strategies for effective teaching. These criteria are notions about knowledge and learning with some pedagogical guidelines. They are as follows: 
- Learning is no longer passive process. Knowledge is unable to be transmitted. Learning only takes place when learners are engaged enabling them to take an active role in determining the direction and progress of learning.

- Learners are not blank slates. The new learning is built on prior experiences and knowledge. So, learner must be provided with opportunities to re-articulate knowledge.

- Learning is constructed through experience, in particular, problem-solving experience. As an instructional strategy, then, it is necessary to construct conceptual conflict and to challenge the adequacy of current knowledge.

- New information will be integrated into the knowledge base when learners master then effectively. These situations should include chances for those learners to re-conceptualize and test the efficacy of new ideas and information in action (p:8).

\subsection{Objective and steps of the suggested model RW}

This model based on constructivism aims mainly at enhancing the twelfth graders reflective thinking skills. The twelfth graders here are asked to pass through 7 steps. These steps are called 7Es. This stands for: Elicit Engage, Explore, Explain, Elaborate, Extend and Evaluate.

The following explanation is the researchers' take on the 7Es that has been adapted from the BSCS 5Es instructional model in America; Engage, explore, explain, elaborate, evaluate. In each lesson, the researchers consider the following steps, a cycle of learning could take many lessons.

1- Elicit. The first step is to find out what the twelfth graders know. I.e. prior knowledge. This is a good opportunity to deal with the twelfth graders misconceptions. This stage is really vital since constructivism theory stands for constructing new knowledge upon the previous one. Another thing, to write an essay the twelfth graders must brainstorm their ideas in order to form logical sentences.

2- Engage. In this stage, teachers want to engage interest and curiosity, by raising the big questions and introducing the new learning through teacher explanation. The teacher might give them a brief explanation or some information about the topic to help them make a prediction or to support the explore stage.

3- Explore, the twelfth grades should be given opportunities to work together following the initial teacher input to solve/explore problems, building concepts through first-hand experience. This stage is independent of you, their teacher but may involve scaffolds depending on the complexity of the task. As the teacher, you should set up the task, but then become the facilitator, helping students by asking questions and observing.

4- Explain. During this stage, the teacher would use what twelfth graders had discovered to help them build the concept/knowledge further. This involve checking and asking questions. Using their knowledge gained from experience to develop the concepts further.

5- Elaborate. This stage is the key in assessing the twelfth graders' progress, knowledge, and understanding. During this stage, they may work independently to demonstrate learning. This is where students formalise and apply their learning. At this stage the scaffolds are removed. Students would be involved in independent practice.

6- Extend. In some lessons, the teacher may need this stage to challenge all learners by encouraging them to apply or extend the concepts and skills in new situations. Students make connections not just in the subject/ideas studied but also beyond it. They are able to apply ideas/generalize and transfer principles.

7- Evaluation. While it is expected that evaluation will continue throughout the process, the evaluate section is the section where the teacher evaluates the learning that has occurred. Also, this stage must involve peer/self-assessment or marking. 


\section{Methodology}

\subsection{Research design}

The researchers adopted the descriptive and constructivist design in building the model in addition to the quasi-experimental design, as it is appropriate for this study. In other words, there were two groups: one control and one experimental with pre and posttests. The groups were randomly assigned into control and experimental. Both groups had pre test in reflective thinking and were post tested by the same test. The experimental group was taught using the suggested model RW, while the control group was taught by the traditional method.

The quasi- experimental design:

$\mathrm{E}: \mathrm{P}_{1} \mathrm{~V}_{1} \mathrm{P}_{2} \Rightarrow \mathrm{E}_{0}$

$\mathrm{C}: \mathrm{P}_{1} \mathrm{O} \mathrm{P}_{2} \Rightarrow \mathrm{C}$

Where:

$\mathrm{E}=($ Experimental Group $)$

$\mathrm{C}=($ Control Group $) \mathrm{C}$

$\mathrm{P}_{1}=$ (Pre-Test)

$\mathrm{V}_{1}=($ Variable $\left.)\right)$

$\mathrm{O}=$ (Off)

$\mathrm{P}_{2}=$ (Post Test)

$\mathrm{E}_{0=}$ ( The successful experimental group)

\subsection{Research Variables}

\section{The study has the following two variables:}

1- The independent variable: This is embodied in the model based on constructivism Read to Write RW.

2- The dependent variable is basically: Reflective thinking

\subsection{The Population and Sample of the Study}

The population of the study constitutes all the twelfth graders in Gaza. The sample is confined to eighty-seven female students who were enrolled in the first semester of the academic year (2019/2020).

The researchers carried out this study at "Hayel Abdul Hameed Secondary School". The school was chosen purposefully but the sample of the study was selected randomly out of two classes. The study sample counted 87 female students at the twelfth grade. The students were assigned purposefully but selected randomly to an experimental group 44, and a control one 43 . Students' age ranges from sixteen to seventeen years.

\subsection{Participants}

A sample of female students at the twelfth grade has been selected. Students were assigned randomly to an experimental group, and a control one. Students' age ranges from sixteen to seventeen years.

\subsection{Instruments}

For accomplishing the target of the current study, the researchers have built reflective thinking skills test.

\subsubsection{Reflective Thinking test}

This practice reflective thinking was supposed to assess the students' ability to think reflectively. The test comprises the following five sections:
1. Inferences
2. Assumptions
3. Deductions
4. Interpreting Information
5. Arguments

\subsubsection{The pilot study}


The test was applied to a random sample of (30) students from Hayel Abdul Hameed Secondary School in Gaza City, who had the same characteristics of the sample of the study. The results were recorded and statistically analyzed to assess the validity and reliability of the test.

\subsubsection{Validity of the test}

\subsection{Internal Consistency Validity}

Table (1): Correlation Coefficient of the Items with the total degree of the test

\begin{tabular}{|c|c|c|c|c|c|}
\hline No. & Correlation Coefficient & Sig. level & No. & Correlation Coefficient & Sig. level \\
\hline 1 & $0.498^{* *}$ & 0.01 & 9 & $0.470^{* *}$ & 0.01 \\
\hline 2 & $0.385^{*}$ & 0.05 & 10 & 0.298 & No \\
\hline 3 & $0.643^{* *}$ & 0.01 & 11 & 0.286 & No \\
\hline 4 & $0.398^{*}$ & 0.05 & 12 & $0.383^{*}$ & 0.05 \\
\hline 5 & 0.320 & no & 13 & $0.702^{* *}$ & 0.01 \\
\hline 6 & $0.585^{* *}$ & 0.01 & 14 & $0.374^{*}$ & 0.05 \\
\hline 7 & $0.442^{*}$ & 0.05 & 15 & $0.473^{* *}$ & 0.01 \\
\hline 8 & $0.449^{*}$ & 0.05 & 16 & $0.475^{* *}$ & 0.01 \\
\hline
\end{tabular}

$* \mathrm{r}$ table value at $\mathrm{df}(28)$ and sig. level $(0.05)=0.361$

$* * \mathrm{r}$ table value at $\mathrm{df}(28)$ and sig. level $(0.01)=0.463$

\subsection{Reflective thinking test content validity}

Table (2): The Correlation Coefficient of each domain with the whole test

\begin{tabular}{|c|c|c|}
\hline No. & Correlation Coefficient & Sig. level \\
\hline 1 & $0.815^{* *}$ & 0.01 \\
\hline 2 & $0.704^{* *}$ & 0.01 \\
\hline 3 & $0.550^{* *}$ & 0.01 \\
\hline 4 & $0.760^{* *}$ & 0.01 \\
\hline 5 & $0.641^{* *}$ & 0.01 \\
\hline
\end{tabular}

$* \mathrm{r}$ table value at $\mathrm{df}(28)$ and sig. level $(0.05)=0.361$

$* * \mathrm{r}$ table value at $\mathrm{df}(28)$ and sig. level $(0.01)=0.463$

As shown in the Table (1) and Table (2), there is a correlation between the domains and the total score of the test at sig. level $(\alpha \leq 0.05)$, which shows a high internal consistency of the Reflective thinking test. This reinforces the validity of the test.

\subsection{Reliability of the test}

The reliability of the test was measured by the (KR20) and Spilt-half techniques.

Table (3): (KR20) and Split half coefficients of the Reflective thinking test.

\begin{tabular}{|c|c|c|c|}
\hline Domains & No. of Items & KR20 & $\begin{array}{c}\text { Split half coefficients } \\
\text { of the test domains }\end{array}$ \\
\hline Reflective thinking test & 16 & 0.75 & 0.75 \\
\hline
\end{tabular}

The results showed that the Spilt-half coefficient was (0.75) and KR20 was (0.75), which indicates that the reliability of the test was high and strong.

\subsection{Difficulty coefficient of the test}

The difficulty coefficient is measured on the pilot study by finding out the percentage of the wrong answers of each item made by the students. The coefficient of difficulty of each item was 
calculated according to the following formula for the pilot study which was (30) students. The findings are shown in Table (4) below.

Table (4): Difficulty coefficient for each item of the Reflective thinking test

\begin{tabular}{|c|c|c|c|}
\hline No. & Difficulty coefficient & No. & Difficulty coefficient \\
\hline 1 & 0.80 & 9 & 0.63 \\
\hline 2 & 0.37 & 10 & 0.53 \\
\hline 3 & 0.47 & 11 & 0.60 \\
\hline 4 & 0.57 & 12 & 0.60 \\
\hline 5 & 0.57 & 13 & 0.53 \\
\hline 6 & 0.47 & 14 & 0.50 \\
\hline 7 & 0.60 & 15 & 0.43 \\
\hline 8 & 0.73 & 16 & 0.57 \\
\hline
\end{tabular}

Table (4) shows the difficulty coefficient wobbled is between $(0.37-0.80)$ with a total mean score of (0.56), which means that each item was acceptable or in the normal limit of difficulty according to the viewpoint of assessment and evaluation specialists.

\subsection{Discrimination coefficient}

Discrimination coefficient means the test is able to differentiate between the high achievers and the low achievers.

Table (5): Discrimination coefficient for each item of the reflective thinking test

\begin{tabular}{|c|c|c|c|}
\hline No. & Discrimination coefficient & No. & Discrimination coefficient \\
\hline 1 & 0.50 & 9 & 0.50 \\
\hline 2 & 0.40 & 10 & 0.30 \\
\hline 3 & 0.80 & 11 & 0.50 \\
\hline 4 & 0.40 & 12 & 0.30 \\
\hline 5 & 0.40 & 13 & 0.80 \\
\hline 6 & 0.70 & 14 & 0.50 \\
\hline 7 & 0.50 & 15 & 0.80 \\
\hline 8 & 0.40 & 16 & 0.80 \\
\hline
\end{tabular}

Table (5) shows that the discrimination coefficient wobbled between $(0.30-0.80)$ with a total average of (0.54), which means that each item was acceptable or in the normal limit of discrimination according to the viewpoint of assessment and evaluation specialists.

\subsection{Controlling the reflective thinking variable}

To make sure that the sample subjects were equivalent in their prior writing, the researchers applied the reflective thinking test. Findings of the subjects were recorded and statistically analyzed using t-test.

Table (6): T-test independent samples findings of differences between the experimental and the control group in the study tools

\begin{tabular}{|c|c|c|c|c|c|c|c|}
\hline \multicolumn{2}{|c|}{ Domain } & Group & $\mathbf{N}$ & Mean & Std. Dev. & $\mathbf{T}$ & Sig. \\
\hline \multirow{7}{*}{$\begin{array}{c}\text { Reflective } \\
\text { thinking test }\end{array}$} & \multirow{2}{*}{ Inference } & Experimental & 44 & 1.00 & 0.89 & \multirow{2}{*}{1.705} & \multirow{2}{*}{0.092} \\
\hline & & Control & 43 & 1.33 & 0.89 & & \\
\hline & \multirow{2}{*}{ Assumption } & Experimental & 44 & 0.89 & 0.81 & \multirow{2}{*}{1.427} & \multirow{2}{*}{0.157} \\
\hline & & Control & 43 & 0.65 & 0.72 & & \\
\hline & \multirow{2}{*}{ Deduction } & Experimental & 44 & 0.80 & 0.82 & \multirow{2}{*}{0.234} & \multirow{2}{*}{0.816} \\
\hline & & Control & 43 & 0.84 & 0.84 & & \\
\hline & Interpreting & Experimental & 44 & 0.68 & 0.88 & 0.591 & 0.556 \\
\hline
\end{tabular}




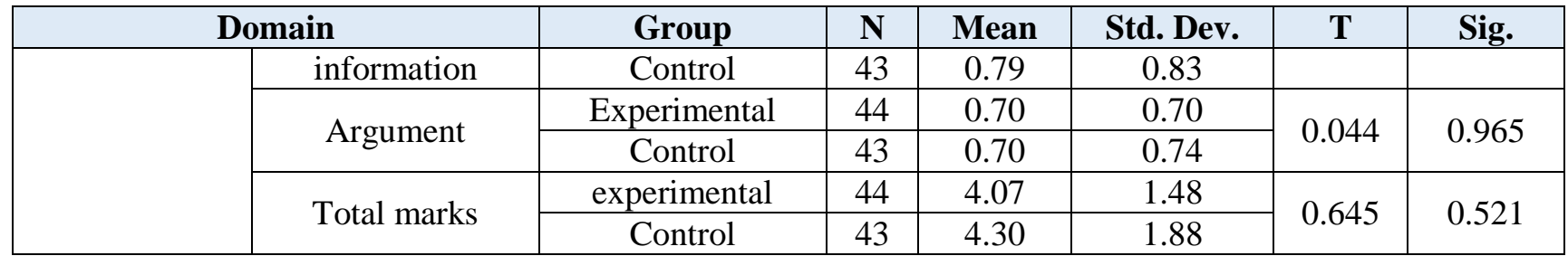

$* \mathrm{t}$ - table value at (85) df. at (0.05) sig. level equal 1.988

** t- table value at (85) df. at (0.01) sig. level equal 2.635

Out of table (6), it can be seen that the analysis of the findings indicates that there were no statistically significant differences between the experimental and the control groups at the significance level $(\alpha \leq 0.05)$.

\subsection{Statistical Methods}

The data of the study was statistically computed using the statistical packager for social sciences (SPSS). The researcher used the following statistical methods:

1. T. Test Independent Samples: to measure the differences in means scores between the experimental group and the control group.

2. Pearson correlation coefficient to identify the correlation the items of the test and the scale.

3. Split-half and Alpha Cronbach techniques were used to the reliability of the scale items.

4. Eta square to assess the effect size.

\section{Results and Data analysis}

This study aimed at investigating The Effect of a Suggested Model Based on Constructivism to Enhance the Reflective Thinking of The Twelfth Graders in Gaza. This section tackles the statistical analysis of the study findings as well as its statistical significance. The researchers used different statistical tests included in the Statistical Package for the Social Sciences (SPSS) to analyze the data collected while answering the study questions and testing the hypotheses.

\subsection{Answers to Research Questions:}

Following is the analysis of the research findings in connection with the study questions and hypothesis.

\subsubsection{Answer to the first question:}

What are the elements of the suggested model that is supposed to help to develop reflective thinking for the twelfth graders?

In order to teach learners in an effective way by using constructivism, Collay (2006) states that constructive learning design must contain six crucial elements. These elements are Situation, Groupings, Bridge, Questions, Exhibit, and Reflections".

- Situation: the first step ever is to set goals, then tasks and curriculum standards.

- Grouping: to group both students and materials. Grouping is a part of cooperative learning.

- Bridge: since constructivism relies mainly on constructing knowledge, it is important to recall prior knowledge using students' cognitive maps, skills, values, motivation, and expectations.

- Questions: the type and organization of questions are vital. Teachers must ask questions that aim at enhancing reflective thinking.

- Task: to use higher level thinking skills and problem-based learning. When designing tasks, they should be problem based.

- Exhibit: to arrange students' portfolios and work samples. (Collay, 2006)

Reflection: synthesize critical thinking and knowledge" Therefore, engaging students in tasks, help them think for themselves, and support them in making meaning of their learning! 
This model has been adopted from a model in Villanova University. The researchers adapted it to the course she teaches. Also, they added some points to enhance reflective thinking during implementing it. The following points were considered during all the sessions.

- Provide enough wait-time for students to reflect when responding to questions.

- Provide emotionally supportive environments in the classroom encouraging conclusions and reducing anxiety.

- Prompt reviews of the learning situation, what is known, what is not yet known, and what has been learned. This is adopted from KWL model.

- Provide authentic tasks involving ill-structured data to encourage reflective thinking during learning activities.

- Prompt students' reflection by asking questions that seek reasons and evidence.

- Provide collaborative environment such as employing peer-group works and small group activities to allow students to see other points of view.

In addition, 7 steps were included in the learning cycle. These are 7Es; Elicit, Engage, Explore, Explain, Elaborate, Extend and Evaluate.

\subsubsection{The answer to the second research question:}

The second research question was formulated as follows:

Are there any statistically significant differences at $(\mathbf{a} \leq \mathbf{0 . 0 5})$ between the mean scores of the experimental group and the control group on the post administration of the reflective thinking test?

To answer this question, the researcher tested the following null hypothesis:

There is no statistically significant difference at $(\mathrm{a} \leq 0.05)$ between the mean scores of the experimental group and the control group in the post administration of the reflective thinking test in favor of the experimental one.

To answer the question and examine the hypothesis, means and standard deviations of both groups findings in the reflective thinking posttest, were computed. Independent Samples T-test was used to measure the significance of the differences. Table (7) describes those results.

Table (7) T-test independent samples findings of differences between the experimental and the control group in reflective thinking in the posttest

\begin{tabular}{|c|c|c|c|c|c|c|}
\hline Domain & Group & $\mathbf{N}$ & Mean & Std. Deviation & $\mathbf{T}$ & $\begin{array}{l}\text { Sig. } \\
\text { value }\end{array}$ \\
\hline \multirow{2}{*}{ Inferences } & experimental & 44 & 2.52 & 0.93 & \multirow{2}{*}{5.145} & \multirow{2}{*}{0.001} \\
\hline & Control & 43 & 1.44 & 1.03 & & \\
\hline \multirow{2}{*}{ Assumptions } & experimental & 44 & 1.70 & 0.98 & \multirow{2}{*}{3.907} & \multirow{2}{*}{0.001} \\
\hline & Control & 43 & 0.88 & 0.98 & & \\
\hline \multirow{2}{*}{ Deductions } & experimental & 44 & 2.00 & 1.01 & \multirow{2}{*}{78} & \multirow{2}{*}{0.001} \\
\hline & Control & 43 & 1.30 & 1.04 & & \\
\hline \multirow{2}{*}{$\begin{array}{l}\text { Interpreting } \\
\text { Information }\end{array}$} & experimental & 44 & 1.82 & 0.97 & \multirow{2}{*}{4.580} & \multirow{2}{*}{0.001} \\
\hline & Control & 43 & 0.88 & 0.93 & & \\
\hline \multirow{2}{*}{ Arguments } & experimental & 44 & 1.66 & 0.91 & \multirow{2}{*}{3.995} & \multirow{2}{*}{0.001} \\
\hline & Control & 43 & 0.91 & 0.84 & & \\
\hline \multirow{2}{*}{ Total } & experimental & 44 & 9.70 & 2.37 & \multirow{2}{*}{8.558} & \multirow{2}{*}{0.001} \\
\hline & Control & 43 & 5.42 & 2.30 & & \\
\hline
\end{tabular}

* t- table value at (85) df. at (0.05) sig. level equal 1.988

$* *$ t- table value at (85) df. at (0.01) sig. level equal 2.635 
The table above shows that significant value was less than $(0.01)$, and $(\mathrm{t})$ calculated was more than $(\mathrm{t})$ tabulated. This means' there were statistically significant differences at $(\alpha \leq 0.05)$ between experimental group and control group in relation to the "mechanics, grammar", and reflective thinking. These differences were in favor of experimental group.

The mean of the post-test in the experimental group was (9.70), whereas that of the control group was (5.42). This result indicates the effect of a suggested model based on constructivism to enhance reflective thinking.

To find out the effect size of the model based on constructivism, the researcher applied the " $\eta "$ formulae. To show the extent of the effect of a suggested model based on constructivism to enhance reflective thinking.

When $\mathrm{d}<0.2$ means small effect size

$$
d=\frac{2 \sqrt{\eta^{2}}}{\sqrt{1-\eta^{2}}}
$$

$$
\eta^{2}=\frac{t^{2}}{t^{2}+d f}
$$

When $0.2 \geq \mathrm{d} \leq 0.8$ means moderate size effect

When $\mathrm{d}>0.8$ means large effect size

Table (8) The effect Size of the experimental group in Reflective Thinking in the posttest

\begin{tabular}{|c|c|c|c|}
\hline Domain & t value & $\boldsymbol{\eta 2}$ & Effect size \\
\hline Inferences & 5.145 & 0.24 & Large \\
\hline Assumptions & 3.907 & 0.15 & Large \\
\hline Deductions & 3.178 & 0.11 & Average \\
\hline Interpreting Information & 4.580 & 0.20 & Large \\
\hline Arguments & 3.999 & 0.16 & Large \\
\hline Total & 8.558 & 0.46 & Large \\
\hline
\end{tabular}

Table (8) proves that the effect of using the constructivist-based model is significant for students' reflective thinking. The results showed that $(46 \%)$ the change in the dependent variable (Reflective Thinking) is due to the effect of the independent variable (Model based on constructivism). This significant impact is due to the constructivist model RW for improving students' reflective thinking. 


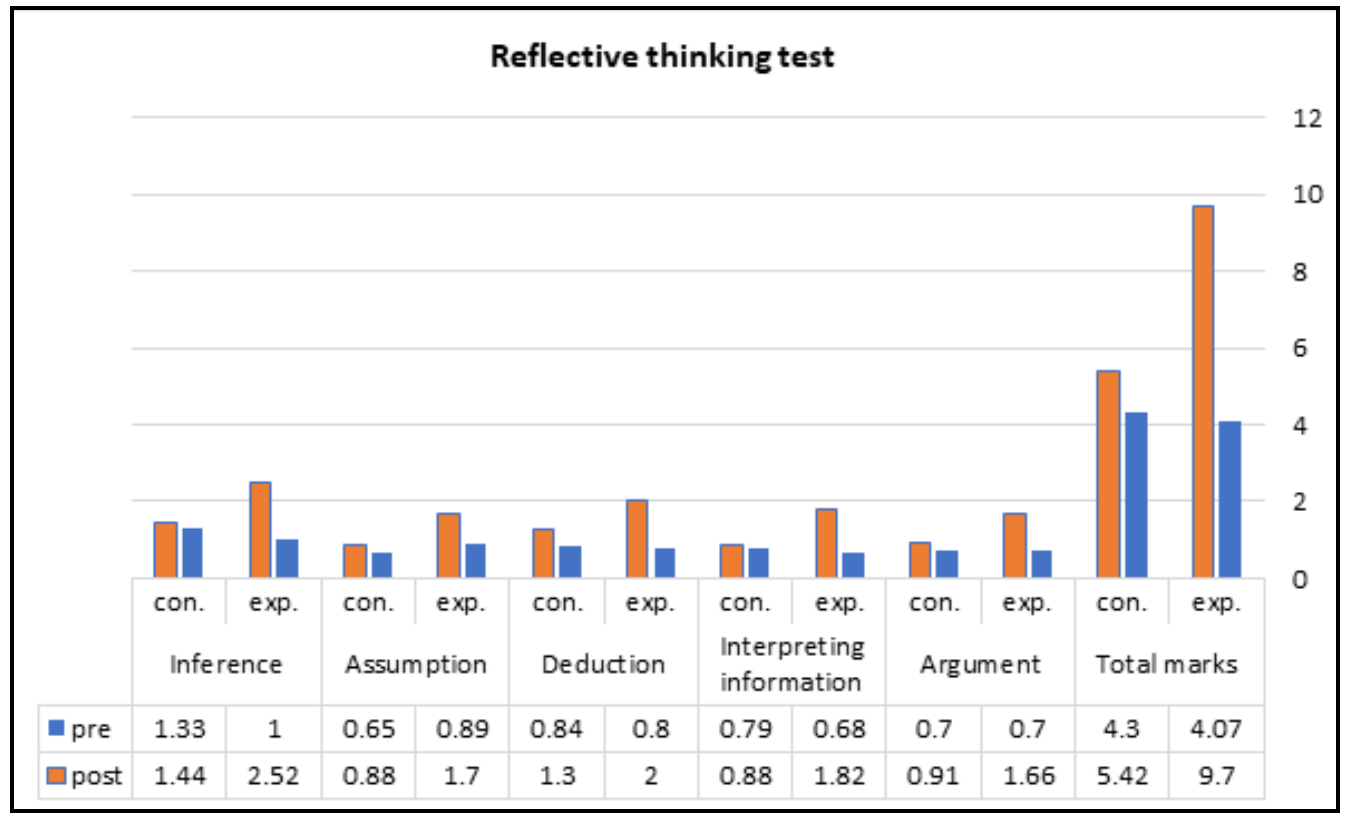

Figure (1): Graphical representation of the reflective thinking test

Figure (1) shows that there is a statistically significant difference at $(\alpha \leq 0.05)$ between Experimental group and Control group in the Reflective thinking test; these differences were in favor of the experimental group. I.e. there is a large positive effect of the use of model based on constructivism on the development of reflective thinking skills (inference, assumption, deduction, interpreting information, argument) of twelfth grade students. The larger effect was in inference skill of reflective thinking followed with deduction skill.

\section{5- Discussion}

Developing reflective thinking through a suggested model based on constructivism for the twelfth graders was really enjoyable and pleasant experience. Of course, it requires the teachers to have much necessary knowledge and many needed skills to build such model.

This RW model based on constructivism was basically designed to enhance reflective thinking skills for the twelfth grade students. in order to develop reflective thinking skills during this instructional model based on constructivism RW, the researchers tended to emerge the skills of reflective thinking in each lesson. For example, the researchers used some techniques like think aloud to be a model for her students as a reflective thinker.

In order to upgrade the twelfth graders abilities to think reflectively, the implementing of this RW model contains some thinking skills leading toward desirable outcomes; to produce reflective thinkers. It focuses on the process of making judgments about what has happened. In addition, there is a place for solving problems because it provides students with an opportunity to step back, to think about how they actually solve problems, and to consider how a particular set of problem solving strategies is appropriated for achievement. The researchers used a cycle of seven steps in this process; 7Es. This stands for: Elicit Engage, Explore, Explain, Elaborate, Extend and Evaluate.

These skills are partly new to the twelfth graders as they are basically are not used to using their thinking abilities. They memorize more than understand. The role was to activate thinking during asking questions such as "what"? "why"? "how"? these questions to enhance interpreting information, inference, investigation and problem solving. She would ask in certain situation; "is 
this applicable in our society? If yes, she asked "how"? if no, she asked "why" and " how to make it possible"?

Few previous studies investigate the effect of implementing constructivist strategies on thinking in general but none investigated the relation between constructivist teaching strategies on reflective thinking. Kwan and Wang (2015) in their study found that there was direct relationship between the constructivist learning environment and critical thinking ability. This study tool was a questionnaire not a test.

This study aimed to enhance reflective thinking of the twelfth grade students. According to the surprising results, the model succeeded in making the twelfth graders think, and also in constructing their own knowledge and experiences including their thoughts and the way they think.

\section{6- Research Recommendations}

This research raises some possibilities for improving reflective thinking for the twelfth graders in Gaza by implementing a new instructional RW model based on constructivism. This model was designed to enhance reflective thinking.

This model RW is based on constructivism. Thus, the implementation of it necessarily requires that teachers make change the way they teach. They should initially understand the constructivist philosophy. Also, administrators and others who are involved in implementing this model need to understand the changes that teachers need to make while moving from traditionalist forms of instruction to this constructivist model. These changes are inevitable in order to get truly better reflective thinkers as well.

The current study attempts to answer some questions, but also raises many other inquiries. No doubt, according to the findings of the study, constructivist teaching model RW had a large positive effect on the twelfth graders' reflective thinking skill. The first inquiry here is how to encourage teachers of English language to build such models or even strategies?

Those teachers cannot be encouraged until they are completely convinced that constructivist-teaching strategies really work. This needs long consistent and practical training by the ministry of education. One must not forget the role of universities in preparing the future teachers.

The following points elaborate this idea:.

- Considering the constructivist nature, it is really essential that administrators as well as teachers and student teachers must have clear idea about constructivism philosophy and its pedagogical applications.

- Considering reflective thinking, apart from being reflective thinkers, EFL teachers should consider reflective thinking in their teaching process.

- Education colleges are responsible for preparing efficient student teachers who are able to design the best tested learning environments which are constructivism based.

The second enquiry raised by this study is: To what extent do teachers work to enhance the learners' thinking skills in general and particularly reflective thinking?

To answer this, some rearchers needs to carry out more research. Studies on the extent our teachers teach reflective thinking and the methods they use should be carried out. In addition, there must be a complete plan to overcome any difficulties on the way.

- To sum up, to ensure the development of reflective thinking skills during formal education, it is basically recommended that these skills are practiced actively by employing suitable models.

\section{References}


branch, w. and paranjape, a. (2002). feedback and reflection: teaching methods for clinical settings. academic medicine journal. doi: 10.1097/00001888-200212000-00005

Brooks, J. And Brooks, M. (1999). In Search of Understanding: the Case for Constructivist Classrooms, Association for Supervision and Curriculum Development. Alexandria. Virginia USA.

Bruner J (1966). Toward a theory of instruction. Cambridge, MA: Belknap Press of Harvard University.

Bolton, G. (2010). Reflective practice: Writing and professional development. Thousand Oaks, CA: Sage.

Buck, J. (2017). An Exploratory Examination of Reflective Thinking in Certified Human Performance Improvement Professionals. kansas state university Manhattan

Collay, M. (2006). Constructivist Learning Design. A collaborative paper. Retrieved on: 27/12/2019,From:file:///C:/Users/Mas/Downloads/Documents/Gagnon Collay_ConstructivistLearningDesign.pdf

Demir, S. (2015). Reflective practice in an early childhood teacher education program: A study of the components of learning about and implementing reflective practice. Journal of Education and Practice.

Dewey, J. (1933). How we think: A restatement of the relation of reflective thinking to the educative process. Massachusetts: D.C. Health and Company.

Dewey, J. (1997). How we think. Mineola. New York: Courier Dover.

Duban N, Yanpar Yelken T (2010). Pre-service teachers' opinions about their reflective thinking tendencies and characteristics of a reflective teacher. C.U. Soc. Stud. Institute J. 19(2):343-360

Facione, P. A. (1990). Critical thinking: A statement of expert consensus for purposes for educational assessment and instruction. Newark, DE: American Philosophical Association.

Fosnot, K. (1989). Constructivism: Theory, Perspectives and Practice. ( $2^{\text {nd }}$ edition). Teachers College, Columbia University New York and London.

Gray, A. (1997). Constructivist teaching and learning. SSTA Research Centre Report. Retrieved on: 15/08/2019. From http://saskschoolboards.ca /research/instruction/97-07.htm

Hoover, W. A. (1996). The practice implications of constructivism. SEDL Letter, 9(3), 1-2.

Irfaner, S. (2006). Enhancing thinking skills in the classroom. Humanity \& Social Sciences Journal, $1(1), 28-36$

Jonassen, D. H. (1992). Evaluating constructivistic learning. In T. M. Duffy \& D. H.

Kelly, G.A. (1991). The psychology of personal constructs. London: Routledge.

Kember, D., Leung, D. Y., Jones, A., Loke, A. Y., McKay, J., Sinclair, K, ... \& Yeung, E. (2000). Development of a questionnaire to measure the level of reflective thinking. Assessment \& Evaluation in Higher education, 25(4), 381-395.

Kwan, Y. Wong, A. (2015). Effects of the constructivist learning environment on students' critical thinking ability: Cognitive and motivational variables as mediators. International Journal of Edcational Research. (70), 68-79

Lee, W. O. (1996). The cultural context for Chinese learners: Conceptions of learning in the Confucian tradition. In D. Watkins \& J.B. Biggs (Eds.), The Chinese learner: Cultural, psychological and contextual influences. Hong Kong: Comparative Education Research Centre, University of Hong Kong.

Leung, D. Y. P., \& Kember, D. (2003). The relationship between approaches to learning and reflection upon practice. Educational Psychology, (23), 61-71.

Mann, K., Gordon, J., \& MacLeod, A. (2009). Reflection and reflective practice in health 
professions education: a systematic review. Advances in Health Sciences Education, 14(4), 595-621.

Mezirow, J. (1991). Transformative dimensions of adult learning. San Francisco, CA: JosseyBass.

McLeod, S. A. (2019, July 17). Constructivism as a theory for teaching and learning. Simply Psychology. https://www.simplypsychology.org/constructivism.html

Osterman, Karen F. (1998). Using Constructivism and Reflective Practice To Bridge the Theory/Practice Gap. Paper presented at the Annual Meeting of the American Educational Research Association

Phan, H. P. (2007). An examination of reflective thinking, learning approaches, and selfefficacy beliefs at the university of the south pacific: A path analysis approach. Educational Psychology, 27(6), 789-806

Piaget, J. (1977). The development of thought: Equilibration of cognitive structures. (A. Rosin, Trans). New York: The Viking Press.

Porntaweekul, S., Raksasataya, S., \& Nethanomsak, T. (2015). Developing reflective thinking instructional model for enhancing students desirable learning outcomes. Educational Research and Reviews, 11(6), 238-251.

Ruggiero, V. R. (2012). The art of thinking: A guide to critical and creative thought. (10 ${ }^{\text {th }}$ edition). New York, NY: Longman.

Schon D.A. (1983). The reflective practitioner: how professionals think in action. New York: Basic Books.

Shandomo, H. M. (2010). The role of critical reflection in teacher education. School-University Partnerships, 4(1), 101-113.

Tweed, R. G., \& Lehman, D. R. (2002). Learning considered within a cultural context: Confucian and Socratic approaches. American Psychologist, 57(2), 89.

Vygotsky, L. S. (1978). Mind in society: The development of higher psychological processes. Cambridge, MA: Harvard University Press.

Wolters, H. M. K., Conrad, T., Riches, C., Brusso, R., Nicely, K., Morath, R, \& Keller-Glaze, H. (2014). Identification of knowledge, skills, and abilities for Army design. Technical Report .

Zemelman, S. Daniels, H. \& Hyde, A. (1993). Best Practice. Bringing schools to life in American classroom. Portsmouth, NH: Heinemann 